\title{
Sorbitol dehydrogenase deficiency in several pig tissues: potential implications for studies of experimental diabetes
}

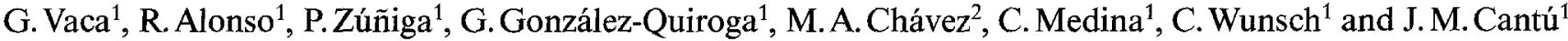 \\ ${ }^{1}$ División de Genética, Subjefatura de Investigación Científica, Unidad de Investigación Biomédica, Centro Médico de Occidente, \\ Instituto Mexicano de Seguro Social Guadalajara, Jalisco, Mexico, and \\ ${ }^{2}$ Catedra de Hematología, Centro de Investigación en Hemoglobinas Anormales y Trastornos Afines, Facultad de Microbiología, \\ University of Costa Rica, San José, Costa Rica
}

Summary. Screening for red blood cell sorbitol dehydrogenase deficiency in 12 different mammalian species was performed. A wide inter-species variability in red cell sorbitol dehydrogenase with a virtually complete deficiency in pigs was observed. Aldose reductase and sorbitol dehydrogenase activities in 12 different pig tissues also were measured. Aldose reductase activity was present in all the tissues studied, whereas organ specificity for sorbitol dehydrogenase was observed.
Sorbitol dehydrogenase activity was not detectable in lenses, among other tissues, making the pig a potential model for studies in experimental diabetes, particularly for the investigation of sorbitol dehydrogenase deficiency as a risk factor in the development of cataracts.

Key words: Aldose reductase, animal models, cataracts, diabetes, red blood cells, sorbitol dehydrogenase.
Sorbitol and galactitol are involved in the pathogenesis of diabetic and galactosemic cataracts in man and experimental animals [1]. Theoretically, a sorbitol dehydrogenase (SORD) deficiency could lead to sorbitol accumulation in lenses, among other tissues, and eventually to cataracts. Recently, we investigated this assumption in the population at risk and found a family with congenital cataracts and red blood cell SORD deficiency [2]. Although our results did not define a clear cataract-SORD deficient aetiopathogenic relationship, they strongly suggest activity polymorphism in red blood cell SORD. The role that SORD deficiency may play in the development of diabetic complications could be studied in an animal model with low levels of this enzyme. Red blood cell SORD activity in several mammals has been demonstrated previously [3].

The aim of this study was to screen for red blood cell SORD deficiency in animals. These results, as well as those for aldose reductase (AR) and SORD activities in several pig tissues, are presented.

\section{Materials and methods}

\section{Animal material}

Blood was drawn and collected in heparin from more than 10 mature animals from each of 12 species: 15 Syrian hamster; 20 balc/C mice; 29 Fort Detrick Dunkin Hartley strain guinea pigs; 20 Sprague-Dawley rats; 17 beagle dogs; 20 New Zealand rabbits; 22 Merino sheep; 10 cattle (Cebu); 10 cattle (Holstein); 20 donkeys; 20 pigs; 19 goats; and 10 horses, all four species mixed breed. Pig tissues were obtained from the slaughter house within $60 \mathrm{~min}$ of butchering and stored at $-20^{\circ} \mathrm{C}$.

\section{Methods}

Homogenates of tissues were prepared according to the method of Op't Hof [4]. The SORD activity in the haemolysates from all the animals was assayed in duplicate by the fluorometric method of Vaca et al. [5] and in pig tissues by the spectrophotometric method of King and Mann [6]. AR was assayed in pig tissues, and in red blood cells of five members of each studied species and five human adults by the spectrophotometric method of Hayman and Kinoshita [7] using DLglyceraldehyde as substrate. Protein determinations were performed according to the method of Lowry et al [8].

\section{Results}

In a pilot experiment carried out in human and animal haemolysates AR activity was not detectable. In relation to the mean SORD activity in erythrocytes, three main groups of animals were found: animals with high activity (hamster, $100 \mu \mathrm{mol}$ product formed. $\mathrm{h}^{-1} \cdot \mathrm{g}$ haemoglobin $^{-1}$, coefficient of variation of the mean $\mathrm{CV}=16 \%$ ); intermediate activity (mouse, guinea pig, rat and $\operatorname{dog}, 11-28 \mu \mathrm{mol}$ product formed. $\mathrm{h}^{-1}$. $\mathrm{g}$ haemoglobin $^{-1}, \mathrm{CV}=14-41 \%$ ) and low activity (rabbit, sheep, goat, cattle, horse and donkey, 1-5 $\mu$ mol product formed. $h^{-1} \cdot g$ haemoglobin ${ }^{-1}, C V=39-59 \%$ ). Red blood cell SORD activity was not detectable in the pig. For comparative purposes, the reference values in our laboratory for human red blood cell SORD in normal adult subjects are $17.5 \mu \mathrm{mol}$ product formed. $\mathrm{h}^{-1} \cdot \mathrm{g}$ haemoglobin ${ }^{-1}, \mathrm{CV}=33 \%$.

The results of AR and SORD activities in pig tissues are shown in Table 1. 
Table 1. Aldose reductase and sorbitol dehydrogenase activities in pig tissues

\begin{tabular}{|c|c|c|}
\hline \multirow[t]{2}{*}{ Tissue } & \multicolumn{2}{|c|}{$\begin{array}{l}\text { Activity } \\
\left(\mu \text { mol product formed. } \min ^{-1} \cdot g \text { protein }\right. \\
-1\end{array}$} \\
\hline & Aldose reductase & Sorbitol dehydrogenase \\
\hline Kidney & $9.52 \pm 1.69(6)$ & $25.12 \pm 8.85(6)$ \\
\hline Liver & $5.75 \pm 1.63(6)$ & $19.10 \pm 5.28(6)$ \\
\hline Pancreas & $1.86 \pm 0.41(6)$ & $4.03 \pm 1.71(2)$ \\
\hline Thyroid & $4.89 \pm 1.21(6)$ & $2.82 \pm 0.57(5)$ \\
\hline Brain & $1.83 \pm 0.31(4)$ & $1.36 \pm 0.30(3)$ \\
\hline Spinal cord & $2.01 \pm 0.68(6)$ & $1.13 \pm 0.27(5)$ \\
\hline Heart & $2.04 \pm 0.59(6)$ & Not detectable (6) \\
\hline Spleen & $2.00 \pm 0.43(6)$ & Not detectable (6) \\
\hline Lung & $2.83 \pm 0.74(6)$ & Not detectable $(6)$ \\
\hline Muscle & $1.49 \pm 0.50(5)$ & Not detectable (5) \\
\hline Lymphnode & $1.97 \pm 0.51(5)$ & Not detectable (2) \\
\hline Lens & $0.58 \pm 0.07(6)$ & Not detectable (6) \\
\hline
\end{tabular}

Results expressed as mean $\pm \mathrm{SD}$; numbers in parentheses are the number of animals studied

\section{Discussion}

Whether AR, as measured by glyceraldehyde-reducing activity, is present in the erythrocytes of the animals studied cannot be defined with the methodology used in the present study. Probably, this enzymatic activity is relatively low, since direct spectrophotometric assay in haemolysates was not possible, as in the case of the human enzyme [9].

Human red blood cell glyceraldehyde-reducing activity of $0.08 \mu \mathrm{mol}$ product formed. $\mathrm{min}^{-1} \cdot \mathrm{g}$ haemoglobin $^{-1}$ estimated by an indirect two-stage spectrophotometric assay has been reported [9].

A high variability in red cell SORD activity was observed in almost all species including human red cell SORD and may represent activity polymorphism [2]. A virtually complete red cell SORD deficiency was observed in all the pigs studied. The role of SORD in red cell metabolism in mammals other than man could be studied in a species showing a wide variation in activity.

Glyceraldehyde-reducing activity was present in all the pig tissues studied. Higher levels were found in the kidney, liver and thyroid while the lens had lower levels. This activity could be due either to true aldose reductase or to hexonate dehydrogenase (HD), an enzyme which has overlapping substrate specificities and other similarities with AR [10]. Therefore, isolation and kinetic characterization would be necessary to elucidate this matter [10]. AR from pig lens and HD from pig liver have been purified and characterized [11, 12]. Both enzymes have many common properties. However, one difference between these enzymes is that glucose is substrate only for AR. HD is present also in pig lens and its properties are similar to those of the liver enzyme [11].

Op't Hof [4] assayed SORD electrophoretically in red blood cells and many swine organs and found enzyme activity only in liver, kidney, thyroid and testis. Evidence for polymorphism, suggesting a SORD tetrameric structure also was obtained $[4,13]$. In the pig tissues that we studied (Table 1) SORD activity was found in kidney, liver, pancreas, thyroid, brain and spinal cord. Both Op't Hof's results [4] and our results indicate organ specificity of SORD expression.

Since AR is present in pig lens [11] and SORD is absent (Table 1), high blood glucose concentrations could result in high levels of sorbitol accumulation. Therefore, in experimental diabetes, the pig should be an excellent model to study whether SORD deficiency is a risk factor in the development of cataracts.

Obviously SORD deficiency is harmless in normoglycaemic pigs, but it could be a risk factor for pathological complications in hyperglycaemia. To the best of our knowledge there are no studies either on the relative frequencies of diabetes in pigs or of "sugar-cataracts" in diabetic pigs.

In conclusion, the present results demonstrate: (a) a wide variability of red blood cell SORD activity among different mammals with a virtual complete deficiency in pigs, and (b) organ specificity of SORD expression in pigs.

\section{References}

1. Van Heyningen $R$ (1976) Sugar alcohols in the pathogenesis of galactose and diabetic cataracts. Birth Defects XII: 295-303

2. Vaca G, Ibarra B, Bracamontes M, García-Cruz D, Sánchez-Corona J, Medina C, Wunsch C, González-Quiroga $G$, Cantú JM (1982) Red blood cell sorbitol dehydrogenase deficiency in a family with cataracts. Hum Genet $61: 338-341$

3. Agar NS (1979) The activity of sorbitol dehydrogenase in some mammalian erythrocytes. Experientia 35: 790-791

4. Op't Hof J (1969) Isoenzymes and population genetics of sorbitol dehydrogenase (EC: 1.1.1.14) in swine (Sus scrofa). Humangenetik $7: 258-259$

5. Vaca $G$, Zúñiga $P$, Medina $C$, Alonso $R$, González-Quiroga $G$, Ortiz-de-Luna RI, Cantú JM (1983) A fluorimetric method for red blood cell sorbitol dehydrogenase activity. J Clin Pathol 36: $697-700$

6. King TE, Mann T (1966) Sorbitol dehydrogenase from spermatozoa. Methods Enzymol 9: 159-163

7. Hayman S, Kinoshita JH (1965) Isolation and properties of lens aldose reductase. J Biol Chem 240: $877-882$

8. Lowry OH, Rosebrough NJ, Farr AL, and Randall RJ (1951) Protein measurement with the Folin phenol reagent. J Biol Chem 193: 265-275

9. Beutler E, Guinto E (1974) The reduction of glyceraldehyde by human erythrocytes. L-hexonate dehydrogenase activity. $\mathrm{J}$ Clin Invest 53: 1258-1264

10. Gabbay KH (1973) The sorbitol pathway and the complications of diabetes. $N$ Engl J Med 288: 831-836

11. Branlant $G$ (1982) Properties of an aldose reductase from pig lenses. Comparative studies of an aldehyde reductase from pig lenses. Eur J Biochem 129: 99-104

12. Branlant $\mathrm{G}$, Biellemann JF (1980) Purification and some properties of aldehyde reductases (EC 1.1.1.2) from pig liver. Eur $J$ Biochem $105: 611-621$

13. Op't Hof J, Wolf U, Krone W (1969) Studies on isozymes of sorbitol dehydrogenase in some vertebrate species. Humangenetik 8 : $178-182$

Received: 11 November 1983

and in revised form: 2 July 1984

Dr. G. Vaca

Apartado Postal 1-3838

Guadalajara, Jalisco

Mexico 